\title{
EVALUATION OF DIFFERENT PROSTHETIC DESIGNS OF IMPLANT ASSISTED REMOVABLE PARTIAL DENTURES USED IN MANDIBULAR KENNEDY CLASS II CASES. A THREE -DIMENSIONAL FINITE- ELEMENT ANALYSIS
}

\author{
Ahmed B. EI Okl * and Enas Mesallum **
}

\begin{abstract}
The purpose: The aim of this study was to evaluate the effect of different designs of removable partial denture (RPD) assisted with distal implant used in the treatment of mandibular Kennedy class II cases on the behavior of oral structures by using Three-dimensional (3D) finite-element analysis (FEA).
\end{abstract}

Materials and methods: A three models of mandibular class II Kennedy arch received three RPD designs were evaluated. The first and the second models received a unilateral removable partial denture (uni-RPD) with RPI clasp on the first bicuspid in the first model and an extra coronal attachment at the distal aspect of the splinted first bicuspid and canine abutments in the second model. The third model received a bilateral removable partial denture (bi-RPD) with RPI clasp on the first premolar and a double Aker clasp on the second premolar and first molar of the opposite side. For each model, a vertical and oblique loads of $100 \mathrm{~N}$ were applied to the second molar area. The created model components were then imported to FEA software (ANSYS).

Results: The first model recorded a significant less stresses at the bone, mucosa and abutment teeth in comparison to the other models but insignificance differences occurred in the total deformations.

Conclusion: The von Mises stress and deformation produced in case of (uni-RPD) design with RPI clasp was better than that occurred with extracoronal attachments and (bi-RPD) designs

KEYWORDS : Kennedy class II partially edentulous, single implant, RPI clasp, extracoronal attachment, 3D FEA.

* Associate Professor of Removable Prosthodontics. Oral and Maxillofacial Prosthodontic. Dep. Faculty of Dentistry, King Abdulaziz University. Jeddah, KSA. Assistant Professor of Removable Prosthodontics Faculty of Dental Medicine, Al Azhar University, (Asuit branch) Egypt

** Assistant Professor of Removable Prosthodontics. Oral and Maxillofacial Prosthodontic. Dep. Faculty of Dentistry, King Abdulaziz University. Jeddah, KSA. 


\section{INTRODUCTION}

Treatment of Kennedy class II partially edentulous cases presents a challenging situation due to absence of posterior tooth support. The difference in displacement between the mucosa of the alveolar ridge and the periodontal ligament of last standing abutment affects the stability and the prognosis of prostheses. ${ }^{1}$ Consequently the abutment teeth are subjected to damaging stresses and the alveolar bone resorption is increased. ${ }^{2}$

Many prosthetic options which used in restoration of the unilateral partially edentulous patients try to follow the biomechanical principles for obtaining a good support, adequate retention and stability. These treatments including bilateral or unilateral removable partial dentures, implant supported fixed or removable partial denture., ${ }^{3,4}$

Several studies calculated the stresses induced by the bilateral and unilateral removable partial dentures under different loads. They came to the conclusion that the stress values obtained in the abutment teeth are more less with the unilateral design and it is below the fatigue limit of the tooth. ${ }^{5}$, ${ }^{6}$ However the clinical use of unilateral removable partial dentures reveals that it has less retention and stability, it still offers more aesthetics and comfort during mastication and speech. ${ }^{6,7}$

Using of a single implant under the base of removable partial dentures distal to the terminal abutment has been suggested to improve the mechanical behavior and eliminate of the destructive forces. It switches the distal extension cases from a tooth- and mucosa borne into a more favorable tooth-implant supported categories which improving the vertical support and stability of the prosthesis. ${ }^{8,9}$

Previous studies compared between unilateral and bilateral implant assisted removable partial dentures (IARPD). They reported that the IA- uni-
RPD is a reliable treatment option for the distal extension cases and more comfortable, also the esthetics and the function were improved which resulting in more patient satisfaction. ${ }^{\mathbf{1 0}-12}$

There are controversies about the type of abutment retainers used with IA- uni-RPD whether it is a clasp or extracoronal attachments. Some authors demonstrated that the attachment reduces the stress around the abutment teeth especially when combined with distal implant also it increases retention, and eliminates the clasp and its metal display. On the other hand other researchers were in contrast to these findings. ${ }^{13-15}$

Three-dimensional (3D) finite-element analysis (FEA) is considered one of the valuable method used today in different fields of biomedical engineering and dental researches. It offers many advantages, including accurate analysis, modification, or optimization of dental design and materials. So it offers a standardizing manufacturing processes and reducing the production costs and failures that may be happened in dental studies. ${ }^{16-19}$

The aim of this study is to evaluate the resulting stresses at different oral structures and dental implants induced by three different designs of mandibular removable partial denture assisted with single distal implant, using a 3D- FEA

\section{MATERIAL AND METHODS}

The current finite element analysis simulates a clinical situation where a mandibular Kennedy class II removable partial denture was assisted by a single implant placed in the second molar area. Based on Geng et al. ${ }^{20}$ three finite element models were prepared as;

Model. 1 : Where a single implant (root form threaded titanium dental implant with a diameter of $3.75 \mathrm{~mm} \& 4.1 \mathrm{~mm}$ in platform diameter and a length of $11 \mathrm{~mm}$ ) * with ball \& socket attachment

\footnotetext{
* Zimmer dental Inc, USA
} 
assist a (uni-RPD), with RPI clasp on the first premolar.

Model. 2: As the first one except an extra coronal attachment with integrated interlock (VarioStud- Snap) ** was used at the distal aspect of the splinted first bicuspid and canine abutment teeth which splinted by two porcelain fused to metal crowns.

Model. 3: Where a single implant with ball \& socket attachment assist a (bi-RPD) with RPI clasp on the first premolar. Cross arch stabilization was made by using double Aker clasp on the second premolar and first molar of the opposite side.

The three models as appeared on the finite element software ANSYS (ANSYS Inc., Canonsburg, PA, USA) screen were demonstrated by (Fig. 1). Each part in the three models was attributed by suitable material.

All materials were assumed to be isotropic, homogenous and linearly elastic and its properties are listed in (Table 1). Set of Boolean operations between the modeled components were performed before obtaining the complete model(s) assembled. Meshing of these components was done by 3D brick solid element "Solid-185" which has three degrees of freedom (translations in main axes directions) the resulted numbers of nodes and elements are listed in (Table 2), and samples for these meshed components are presented as screen shots from ANSYS screen in (Fig. 2). The lowest plane of each model was considered as fixed nodes in the three directions as a boundary condition. For each model, a vertical and $10^{\circ}$ angle oblique loads of $100 \mathrm{~N}$ were applied to the second molar area and tested.

Linear static analysis was performed on a Workstation HP Z820 (Dual Intel Xeon E5-2670 v2 processors, $2.5 \mathrm{GHz}, 64.0 \mathrm{~GB}$ RAM), using commercial multipurpose finite element software package (ANSYS version 16.0), that results of these models were verified against similar studies. ${ }^{\mathbf{2 0 , 2 1}}$

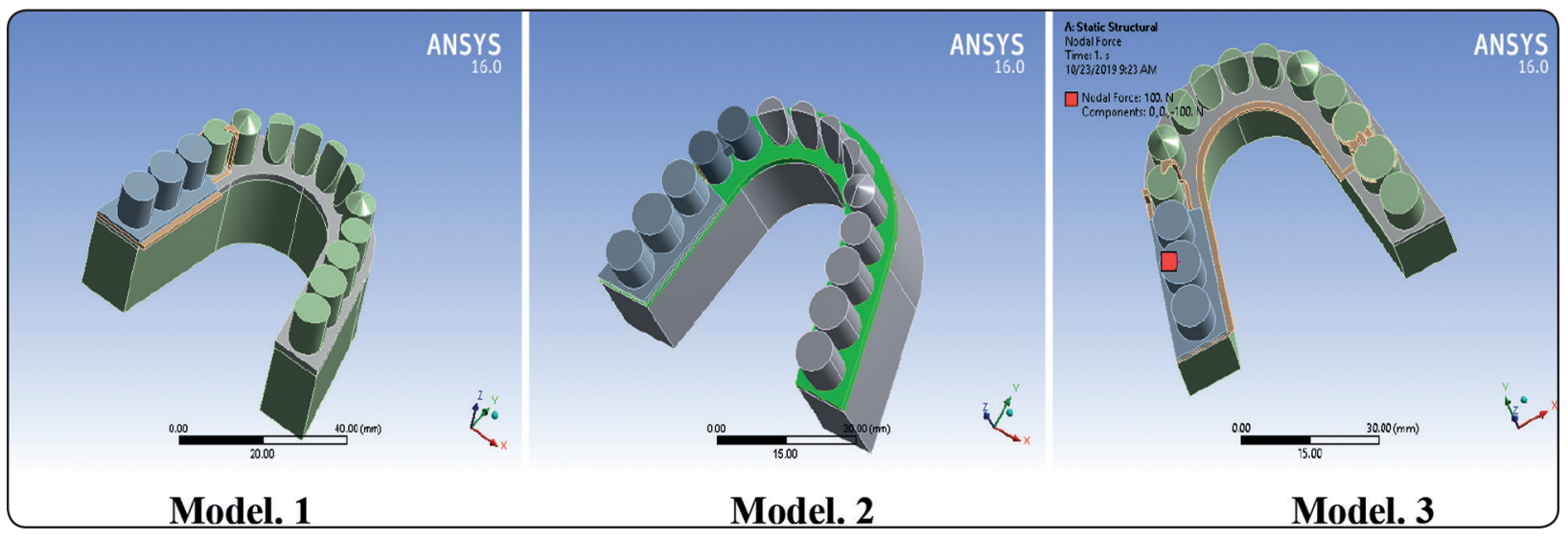

Fig. (1): Three models geometry

** Bredent company, GmbH \& CokG. Weissenhorner Str.2.89250 Senden. Germany. 




Fig. (2): Meshed models from ANSYS screen

TABLE (1) : Material properties used in the finite element model

\begin{tabular}{|l|c|c|}
\hline & Young's Modulus & Poissons Ratio \\
\hline Bone & MPa & -- \\
\hline Mucosa & 13,600 & 0.26 \\
\hline Cobalt-chromium (Framework) & 680 & 0.45 \\
\hline Ni-Cr & 218,000 & 0.33 \\
\hline Zink Phosphate Cement & 205,000 & 0.33 \\
\hline Porcelain & 13,720 & 0.35 \\
\hline Poly methyl metha acrylate & 68,900 & 0.28 \\
\hline Titanium & 8,300 & 0.28 \\
\hline Rubber & 110,000 & 0.35 \\
\hline Nylon & 2,400 & 0.39 \\
\hline
\end{tabular}

TABLE (2): Number of nodes and elements in all meshed components

\begin{tabular}{|c|c|c|c|c|c|c|}
\hline & \multicolumn{2}{|c|}{ Model \#1 } & \multicolumn{2}{c|}{ Model \#2 } & \multicolumn{2}{c|}{ Model \#3 } \\
\hline & Nodes & Elements & Nodes & Elements & Nodes & Elements \\
\hline Bone & 211,512 & 143,956 & 186,592 & 125,290 & 259,669 & 177,825 \\
\hline Mucosa & 41,188 & 26,272 & 15,142 & 7,924 & 44,043 & 28,257 \\
\hline Denture 1 & 123,296 & 83,075 & 73,913 & 49,487 & 129,403 & 85,705 \\
\hline Rubber & --- & --- & 15,812 & 11,094 & -- & $-1,-$ \\
\hline Denture 2 & --- & --- & 41,759 & 24,672 & -- & -- \\
\hline Cement & --- & --- & 70,110 & 34,769 & - & -- \\
\hline Implant & 27,075 & 18,052 & 27,075 & 18,052 & 27,075 & 18,052 \\
\hline Ny Cap & 5,195 & 3,314 & 5,195 & 3,314 & 5,195 & 3,314 \\
\hline Metal Cap & 2,785 & 1,327 & 2,785 & 1,327 & 2,785 & 1,327 \\
\hline
\end{tabular}




\section{RESULTS}

Summary of von Mises stress (MPa) and deformation $(\mathrm{mm})$ produced within a different components of the models used in this study is presented in (Table.3) and (Table. 4) and (Fig. 3).

\section{1- von Mises stress (MPa) and deformation (mm) occurred at different components and tissues due to application of a vertical loads:}

The von Mises stress and deformation generated at the bone in the first model showed a slightly less stress value in comparison to the other two models. The values were $(1.123,1.142,1.128 \mathrm{MPa})$ respectively for model 1, 2, and 3. However this difference is insignificant. While all models showed the same values of total deformation.

The mucosa is fairly relaxed under the first and third models (0.626 and $0.623 \mathrm{MPa})$ this decreasing of von Mises stress is significant when compared with that of the second model $(0.730 \mathrm{MPa})$. But there is no significant difference between the models in respect to the total deformation.

On the other hand a maximum stresses and deformations on the overdenture appeared under the load point without any significant difference between all models.

Concerning the von Mises stress and deformation occurred in the abutment teeth ( $1^{\text {st }}$ premolar and canine) the first model recorded a significant minimum value in stress and insignificant decrease in the amount of deformation $(0.170 \mathrm{MPa}, 0.000218$ $\mathrm{mm}$ ) followed by the third model $(0.185 \mathrm{MPa}$, $0.000256 \mathrm{~mm}$ ) while more stress and deformation recorded with the second model (0.267 $\mathrm{MPa}$, $0.000278 \mathrm{~mm}$ )

Although the nylon and metal caps were not sensitive to the design used, an insignificant increasing of stresses about 3\% appeared at implant with the third model $(6.0056 \mathrm{MPa})$. The total deformation values are almost same for all models.

\section{2- Von Mises stress (MPa) and deformation (mm) occurred at different components and tissues due to application of an oblique load:}

The first model generated a significant less stresses at the bone in comparison to the other models by about $10 \%$ (1.231 MPa) while the other two models showed nearly equivalent behavior $(1.318,1.325 \mathrm{MPa})$ Also insignificance differences occurred in the total deformations at the bone with all models.

Mucosa showed a significant less von mises stresses under first and third model $(0.605,0.603$ $\mathrm{MPa})$ in regard to the stresses occurred under the second one (0.689 MPa). While the difference of total deformation values between the three models is insignificant.

There is no significance differences in stresses and deformation values recorded at the overdenture in all models.

von Mises stress value recorded at the abutment teeth in the first model $(0.447 \mathrm{MPa})$ followed by the third one $(0.463 \mathrm{MPa})$ while more stress observed with the second model ( $0.562 \mathrm{MPa})$.

Although the total deformation of the abutment teeth was of order 1 micron in models 1 and 3 , while the second model was about 0.9 micron (i.e. $10 \%$ difference) it will not be considered of important significance due to the small values.

For the implant, nylon and metal caps, the von Mises stress and total deformation is almost same for the three models without any significant differences. 
TABLE (3): Von Mises stress (MPa) and deformation ( $\mathrm{mm}$ ), in different components of overdenture and its supporting tissues due to application of a vertical loads of $100 \mathrm{~N}$ at the second molar area, * shows significant

\begin{tabular}{|c|c|c|c|c|c|c|}
\hline \multirow{2}{*}{ Model Components } & \multicolumn{3}{|c|}{ Von Mises stress } & \multicolumn{2}{c|}{ deformation } \\
\cline { 2 - 7 } & Model-1 & Model-2 & Model-3 & Model-1 & Model-2 & Model-3 \\
\hline Bone & 1.123 & 1.142 & 1.128 & 0.00092 & 0.00092 & 0.00092 \\
\hline Mucosa & 0.626 & 0.730 & $0.623^{*}$ & 0.00130 & 0.00128 & 0.00128 \\
\hline Overdenture & 62.454 & 62.454 & 62.454 & 0.021 & 0.021 & 0.021 \\
\hline Abutment teeth & $0.170^{*}$ & 0.267 & 0.185 & $0.000218^{*}$ & 0.000278 & 0.000256 \\
\hline Implant & 5.866 & 5.860 & 6.0056 & 0.00043 & 0.00042 & 0.00042 \\
\hline Nylon Cap & 0.0462 & 0.0463 & 0.046 & 0.00061 & 0.00061 & 0.00061 \\
\hline Metal Cap & 2.194 & 2.193 & 2.204 & 0.00063 & 0.00063 & 0.00063 \\
\hline Rubber & & 2.4423 & & & 0.00017 & \\
\hline Porcelain crowns & & 51.225 & & & 0.00019 & \\
\hline Cement & & 0.157 & & & 0.00018 & \\
\hline
\end{tabular}

TABLE (4): Von Mises stress (MPa) and deformation ( $\mathrm{mm}$ ), in different components of overdenture and its supporting tissues due to application of an oblique loads of $100 \mathrm{~N}$ at the second molar area, * shows significant

\begin{tabular}{|c|c|c|c|c|c|c|}
\hline \multirow{2}{*}{ Model Components } & \multicolumn{3}{|c|}{ von Mises stress } & \multicolumn{3}{|c|}{ Deformation } \\
\hline & Model-1 & Model-2 & Model-3 & Model-1 & Model-2 & Model-3 \\
\hline Bone & $1.231 *$ & 1.318 & 1.325 & 0.00166 & 0.00166 & 0.00165 \\
\hline Mucosa & 0.605 & 0.689 & $0.603 *$ & 0.00209 & 0.00213 & 0.00208 \\
\hline Overdenture & 59.563 & 59.563 & 59.563 & 0.0215 & 0.0215 & 0.0215 \\
\hline Abutment teeth & $0.447 *$ & 0.562 & 0.463 & 0.001008 & 0.000882 & 0.001004 \\
\hline Implant & 5.249 & 5.257 & 5.423 & 0.00157 & 0.00155 & 0.00155 \\
\hline Nylon Cap & 0.041 & 0.042 & 0.042 & 0.00178 & 0.00176 & 0.00179 \\
\hline Metal Cap & 1.872 & 1.894 & 1.885 & 0.00181 & 0.00179 & 0.00179 \\
\hline Rubber & & 10.116 & & & 0.00085 & \\
\hline Porcelain crowns & & 221.95 & & & 0.00092 & \\
\hline Cement & & 0.647 & & & 0.00088 & \\
\hline
\end{tabular}




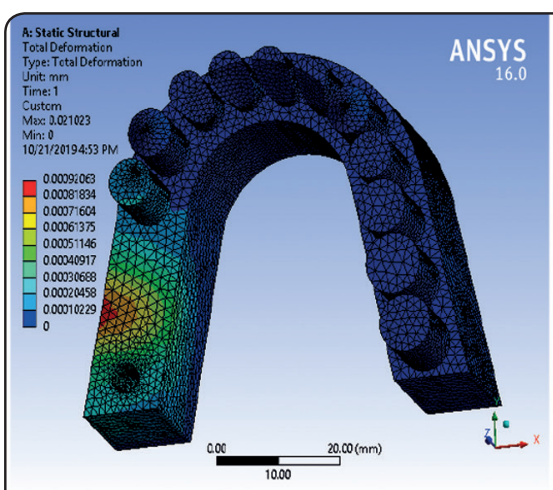

(a)

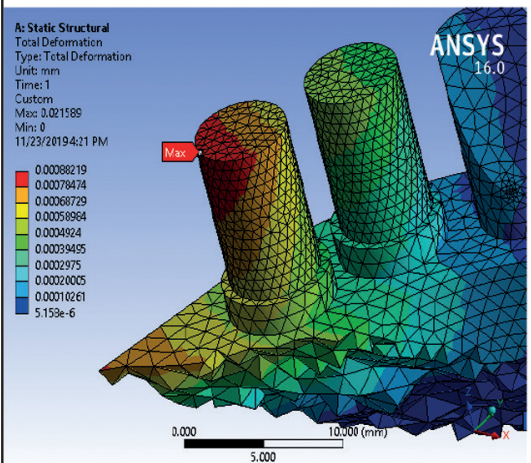

(d)

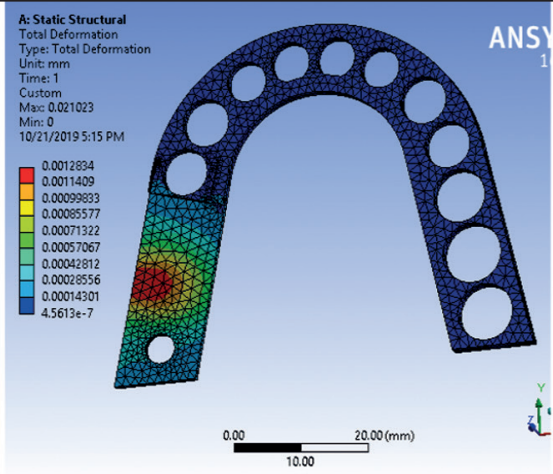

(b)

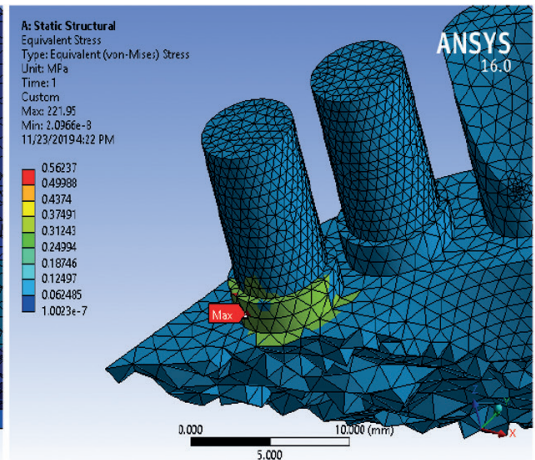

(e)

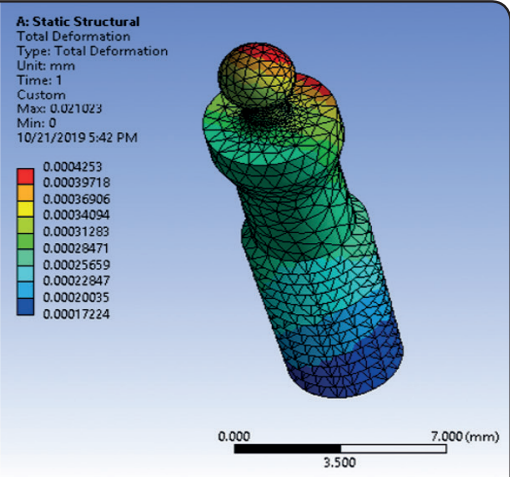

(c)

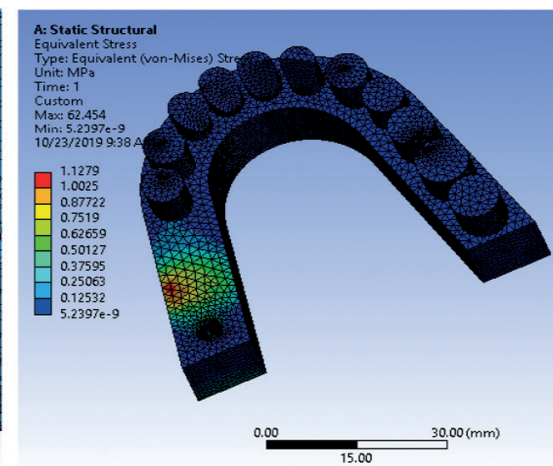

(f)

Fig.(3). Illustrate a stress distribution and total deformation at selected components of the three models. (a-c) Model \#1 total deformation of (bone, Mucosa and implant) under vertical load, (d) Model \#2 total deformation of abutments under oblique load, (e) Model \#2 stresses distribution at abutments under oblique load (f) Model \#3, stress distribution at the bone.

\section{DISCUSSION}

Intraoral evaluation of stress behavior of different tissues is difficult to be accurate and standard so the present study was run in-vitro by using the threedimensional finite-element analysis. It is a precise and reliable way used to measure the stress and strain distributions in different oral structures. ${ }^{22-27}$ Also this method generate a primary data for new clinical therapy and detection of possible clinical implications.

Using an implant-assisted RPDs in distal extension case is an acceptable treatment modality, it change the Kennedy class II to a more favorable class III so the harmful horizontal forces is avoided. In addition many investigations suggested that implants should be placed closer to second molar to provide better occlusal support and biomechanical configuration . 28-30

Furthermore a load of $100 \mathrm{~N}$ was applied. The normal occluding force of partially edentulous cases wearing removable partial dentures has been reported to be ranged from 70 to 200 N. ${ }^{31}$

Regarding to stresses and the deformation values recorded at the bone, the abutment teeth and the mucosa, the unilateral partial denture showed more favorable results than the bilateral and extra coronal attachment designs.

This may be due to the fact that, applying the load at the central fossa is balanced between supporting structures (implant and abutment tooth) which 
minimize or eliminate the effect of having bilateral support. Moving the loading point slightly lingual or buccal may be increase the effect of bilateral design. ${ }^{32}$

Also the traditional RPI clasp transfer the applied load to the supporting tooth as preferred compressive load, while interlock connection will result in transferring the applied load as bending moment on the supporting tooth. Thus it will be expected that RPI clasp will generate less stresses on supporting tooth in comparison to interlock connection. ${ }^{32}$

These findings are similar to previous studies 5, 33, 34 which concluded that the stresses applied to the abutment tooth by a clasp retained unilateral partial denture were within the physiological limits so it is considered as a viable treatment option. This is emphasized by Radović et al ${ }^{35}$ who stated that the clasp retained unilateral design proved good performance indicators and greater patient satisfaction.

Pellizzer et al ${ }^{36}$ reported that the supporting structures showed a satisfactory behavior under implant-supported unilateral removable partial denture regarding when a favorable load was applied. In addition the destructive forces were eliminated and the retention was increased. ${ }^{12,37,38}$

In the same context, different authors stated that the semi precision and precision attachment designs caused a more stresses at the abutment teeth than the clasp design partial dentures. ${ }^{39,40}$

On the other hand our findings is disagreements to previous studies who told that the stresses recorded at the abutment teeth and implant in case of implantsupported unilateral removable partial denture were higher than that occurred in bilateral or extra coronal attachment designs. This contradiction may be explained by the fact that their studies performed on short edentulous span. ${ }^{41,42}$

\section{CONCLUSIONS}

Within the limitation of this in vitro study we can concluded that:

The von Mises stress and total deformation induced at the alveolar bone, mucosa and abutment teeth were more favorable in case of RPI clasp retained a (uni-RPD) than that recorded in the (uni-RPD) with the extracoronal attachments and (bi-RPD) designs.

\section{ACKNOWLEDGEMENT}

The authors would like to thank the professor Mohamed El-Anwar for their role in running the finite-element analysis used in this study.

\section{REFERENCES}

1. Grasso JE, Miller EL. Removable partial prosthodontics. $2^{\text {nd }}$ ed. Toronto, Philadelphia: B.C. Decker Inc. 2008; P.137-51

2. Ozan O, Orhan K, Aksoy S, Icen M, Bilecenoglu B, and Sakul BU. The Effect of removable partial dentures on alveolar bone resorption. A retrospective study with cone-beam computed tomography. J Prosthodont; 2013; 22(1):42-50.

3. Abraham PA, Koka P, Murugesan K, Vasanthakumar M. Telescopic overdenture supported by a combination of tooth and an implant: a clinical report. J Indian Prosthodont Soc 2010;10 (4):230-233

4. Carr AB, Brown DT. McCraken's removable partial prosthodontics. 12th ed. St Louis: Mosby Co. 2011; p. 103-15; p. 6, 21

5. Radovic K, Cairovic A, Todorovic A, Stančic I, and Grbovic A. Comparative analysis of unilateral removable partial denture and classical removable partial denture by using finite element method. Srp Arh Celok Lek 2010 ; 138(11-12):706-719

6. Todorovi A, Radovi K, Grbovi A, Rudolf R, Maksimovi I, and Dragoslav S. Stress analysis of a unilateral complex partial denture using the finite-element method. Materials and Technology 2010; 44(1):41-47.

7. Kwing-chi L, Tzung-shium T, Shen-chi H. Unilateral rotational path removable partial dentures for tilted mandibular molars design and clinical applications. J Prosth Dent 1997; 8:102 -105 
8. Ramchandran A, Agrawal KK, Chand P, Ramashanker, Singh RD, Gupta A. Implant-assisted removable partial denture: An approach to switch Kennedy Class I to Kennedy Class III. J Indian Prosthodont Soc 2016; 16:408-411.

9. Jensen C, Raghoebar GM, Kerdijk W, Meijer HJ, Cune MS. Implant-supported mandibular removable partial dentures; patient-based outcome measures in relation to implant position. Journal of dent. 2016; 55: 92-98.

10. Fayyad A. Clinical management of Kennedy class II cases using osseointegrated dental implants. Doctor Thesis in Prosthodontics, 2012- Cairo University.

11. Alam-Eldein AM, Abd El Fattah FE, and Shakal EA . Comparative study of two different designs of partial over denture supported with distal implant for the treatment of mandibular Kennedy class II cases. Tanta Dent J 2013; 10 (2): $39-47$

12. Carpenter JF. Implant-assisted unilateral removable partial dentures. Dent Today 2014; 33(1):106-115

13. Jain AR, Philip JM, Ariga P. Attachment-retained unilateral distal extension (Kennedy's class II modification I) cast partial denture. Int J Prosthodont Restor Dent. 2012; 42(3):101-107.

14. Ramchandran A, Agrawal KK, Chand P. Implant-assisted removable partial denture: An approach to switch Kennedy Class I to Kennedy Class III. The Journal of the Indian Prosthodontic Society 2016; 16(4):408-411.

15. Eitaftazani EA, Aziz EA and Moubarak AH. What is after conversion of unmodified kennedy class II into kennedy class III cases? Egyptian Dental Journal. 2004; 50: 16131625

16. Shamsi-Sarband A., Zahedi, S.A., Bakhshi-Jouybari, M., Hossinipour S.J., Banabic, D.Optimization of the pressure path in sheet metal hydroforming. Proceed Roman Acad. 2012; 13:351-359.

17. Zahedi, S.A., Demiral, M., Roy, A., Silberschmidt, V.V. FE/SPH modelling of orthogonal micro-machining of f.c.c single crystal. Comput Mater Sci. 2013; 78:104-109.

18. Seung-Ryong, H., Sung-Hun, K., Jai-Bong, L., Jung-Suk, H., In-Sung, Y., Seung-Hyun, Y. Effects of coping designs on stress distributions in zirconia crowns: Finite element analysis. Ceram. Inter 2016; 42: 4932-4940.

19. Doundoulakis JH, Eckert SE, Lindquist CC, Jeffcoat MK. The implant-supported overdenture as an alterna- tive to the complete mandibular denture. J Am Dent Assoc 2003;134:1455-1458.

20. Geng J, Yan W, Xu W, editors. Application of the finite element method in implant dentistry. Springer Science \& Business Media; 2008.

21. El-Anwar MI, Yousief SA, Soliman TA, Saleh MM, Omar WS. A Finite element study on stresses distribution of two different attachment designs under implant supported overdenture. The Saudi Dental Journal. 2015; 27(4):201207

22. Asundi A, Kishen A. A strain gauge and photoelastic analysis of in vivo strain and in vitro stress distribution in human dental supporting structures. Arch Oral Biol 2000; 45(7): 543-50.

23. Liu J, Pan S, Dong J, Mo Z, Fan Y, Feng H. Influence of implant number on the biomechanical behavior of mandibular implant-retained/supported overdentures: A three-dimensional finite element analysis. J Dent 2013; 41:241-249.

24. Gonda T, Dong J, Maeda Y. Stress analysis of an overdenture using the finite element method. Int J Prosthodont $2013 ; 26: 340-342$.

25. Bilhan AS, Baykasoglu C, Bilhan H, Kutay O, Mugan A. Effect of attachment types and number of implants supporting mandibular overdentures on stress distribution: A computed tomography-based 3D finite element analysis. J Biomech 2015; 48:130-137.

26. Ozan O, Ramoglu S. Effect of implant height differences on different attachment types and peri-implant bone in mandibular two-implant overdentures: 3D finite element study. J Oral Implantol 2015; 41:50-59.

27. Coelho LF, Broilo JR, Sartori EA, Mariano LO, Geremia T, Barcellos L. Corso LL, Shinkai RS, Grossi ML. Stress distribution study using the finite element method in three different implant-supported fixed complete-arch mandibular prostheses. Int J Prosthodont 2016; 29 (3):299-302.

28. DeFreitas RF, de Carvalho Dias K, da Fonte Porto Carreiro A, Barbosa GA, Ferreira MA. Mandibular implantsupported removable partial denture with distal extension: a systematic review. J Oral Rehabil 2012; 39(10):791-798.

29. Maeda Y, Sogo M, Tsutsumi S. Efficacy of a posterior implant support for extra shortened dental arches: a biomechanical model analysis. J Oral Rehabil 2005; 32 (9):656-660. 
30. Grossmann Y, Nissan MJ, and Levin L. Clinical effectiveness of implant-supported removable partial dentures- a review of the literature and retrospective case evaluation. J Oral Maxillofac Surg 2009; 67(9):1941-1946.

31. Fernandes CP, Glantz PO, Nilner K. On the accuracy of some in vitro models for mechanical studies of maxillary removable partial dentures. Dent Mater 2003; 19(2): 127-136.

32. Floriana L, Michele R, Cervino G, Fiorillo L, Bramanti E, Marco C. Three dimensional evaluation of different implant prosthetic retention systems: FEM E Von Mises Study. Minerva Stomatologica 2016 Dec; 65(6): 353- 367.

33. Ibrahim AM, Swelem AA, and Elkhadem AH. The effect of splinting, tissue contact and denture base material on attachment-retained unilateral removable partial dentures and their supporting structures: a 3-dimensional finite element analysis. Egyptian Dent J 2009; 55: 1751-1763.

34. Todorovi A, Radovi K, Grbovi A, Rudolf R, Maksimovi I, and Dragoslav S. Stress analysis of a unilateral complex partial denture using the finite-element method. Materials and Technology 2010; 44(1):41-47.

35. Radović Katarina, Rade Živković1, Jovana Kuzmanovic Pficer, Ljiljana Tihaček Šojić1, Aleksandra Milić Lemić1: Unilateral complex partial denture performance evaluation: 5 years follow up clinical study. Serbian Dental Journal 2018; 65(3): 140-147
36. Pellizzer E. P., Luersen M. A., Rocha E. P. Finite element analysis of masticatory force in distal-extension removable partial denture associated with an implant. Journal of Dental Research 2003; (82): 25-28

37. Mahn DH. Stabilizing and securing an RPD-with a single implant. Dent Today 2011; 30(9):124-126.

38. Fu MC, Shen YW, and Fuh LJ. Clinical application of implant-supported bilateral distal extension removable partial denture -case report. J Dent Sci 2007; 2(1):52-56.

39. Chou TM, Eick JD, Moore DJ, Tira: DE. Stereophotogrammetric analysis of abutment tooth movement in distalextension removable partial dentures with intracoronal attachments and clasps. J Prosthet Dent.1991; 66(3):343-349.

40. Chou TM, Caputo AA, Moore DJ, Xiao B, Sakumura JS Photoelastic analysis and comparison of force transmission characteristics of intracoronal attachments with clasp distal-extension removable partial dentures. J Prosthet Dent 1989; 62: 313-319

41. Dahab I.A., El-Gendy A.A., Eltorky I.R. In vitro stress analysis study of different prosthetic options using single posterior implant for management of mandibular unilateral distal extension saddle. Tanta Dental Journal 2015;12:7-15

42. Gharehchahi J, Asadzadeh N, Mirmortazavi A, and Shakeri MT. Maximum dislodging forces of mandibular implant-assisted removable partial dentures: in vitro assessment. J Prosthodont 2013; 22(7):543-552. 